\title{
BEZERRAS DE CORTE INFECTADAS NATURALMENTE COM PARASITAS GASTRINTESTINAIS - EPIDEMIOLOGIA E TRATAMENTO SELETIVO
}

\author{
(Naturally infected beef heifers with gastrintestinal parasites - epidemiology \\ and selective treatment)
}

\author{
MOLENTO, M.B. ${ }^{1}$; ALMEIDA, M. ${ }^{2}$; GUTERRES, E. ${ }^{2}$; ROMAN, J. ${ }^{2}$ FREITAS, F. ${ }^{3}$; ROCHA, M. ${ }^{4}$ \\ 1Setor de Doenças Parasitárias - DMVP - Universidade Federal de Santa Maria - UFSM; \\ ${ }^{2}$ Acadêmico do Curso de Medicina Veterinária - UFSM-RS; \\ ${ }^{3}$ Acadêmico de Pós-Graduação - Departamento de Zootecnia - UFSM-RS; \\ ${ }^{4}$ Setor de Forragicultura - Departamento de Zootecnia - UFSM-RS.
}

RESUMO - A severidade das infecções parasitárias depende em grande parte da quantidade e do tipo de parasita presente e do estado nutricional dos animais. $O$ objetivo deste experimento foi associar o efeito da suplementação protéica e pastagem de alta qualidade com diferenças na resposta ao desafio parasitário em 36 novilhas de oito meses, naturalmente infectadas, durante 120 dias. Grupo I: pastagem (Avena strigosa e Lolium multiflorum); Grupo II: pastagem e níveis crescentes de suplemento (Triticum aestivum, farelo de trigo) de 0,3 a 1,5\% do peso vivo (PV); Grupo III: pastagem e suplemento a $0,9 \%$ do PV e Grupo IV: pastagem e níveis decrescentes de suplemento. O grau de infecção parasitária foi determinado através da contagem de ovos por grama de fezes (OPG) e coprocultura. Animais com OPG acima de 600 foram tratados com levamisole (Riperco ${ }^{\circledR}$, Fort Dodge). A coprocultura revelou os gêneros Cooperia spp. e Trichostrongylus spp. O ganho de peso, o escore corporal e o nível parasitário foi semelhante entre os grupos. Foram administradas 24 doses de anti-helmíntico com baixo grau de repetibilidade dos animais. Determinou-se que o tratamento seletivo pode ser aplicado quando os animais dispõem de pastagem de alta qualidade e com baixo desafio parasitário, independente de suplementação alimentar.

Palavras chave: terneiras, parasitas, tratamento seletivo, antiparasitário.

ABSTRACT - The severity of parasite infections depends in part by the number and the parasite species as well as on the nutritional status of the host. The objective of this work was to determine the association between protein supplement and good quality pasture with parasite challenge infection in 36 naturally infected, 8 months old beef heifers during 120 days. Group I: pasture (Avena strigosa and Lolium multiflorum); Group II: pasture plus increasing levels of supplement (Triticum aestivum, wheat bran) from 0.3 to $1.5 \%$ of live weight (LW); Group III: pasture plus $0.9 \%$ LW of supplement; Group IV: pasture plus decreasing levels of supplement. Parasite infection was determined through fecal egg counts (EPG) and coproculture. All animals with EPG above 600 were treated with levamisole (Ripercol ${ }^{\circledR}$, Fort Dodge). Coproculture displayed Cooperia sp. and Trichostrongylus sp. Weight gain, body condition score and parasite levels were similar among all groups. Twenty-four doses of the anthelmintic were administered with low animal repeatability. It was determined that the selective treatment may be used when animals have access to good quality pasture and a low parasite challenge, independently of the supplement offered.

Key-words: heifers, parasites, selective treatment, antiparasitic drug.

\footnotetext{
${ }^{1}$ Autor para correspondência: Cidade Universitária - Santa Maria - RS - CEP 97105-900. Fone: 55 - 3220 - 8071 , FAX: 55 - 3220 - 8257. E-mail: molento@smail.ufsm.br.
} 


\section{Introdução}

O parasitismo gastrintestinal é uma das enfermidades mais importantes de bovinos, sendo a maior causa de perdas na produção mundial (VERCRUYSSE e DORNY, 1999). Essencialmente todo o rebanho em condições de campo pode albergar certo grau de infecção por nematódeos, que resulta em uma complexa série de eventos patológicos que variam de efeitos subclínicos, perdas na produção e até a morte do animal.

A relação parasita-hospedeiro se caracteriza como uma relação de equilíbrio, sendo controlada pela variabilidade intra-específica do hospedeiro e do parasita, aliado a fatores ambientais. O controle parasitário, objetiva perturbar esse equilíbrio, reduzindo o grau de infecção tanto no hospedeiro como no meio ambiente (BISHOP e STEAR, 2003). Tradicionalmente o combate das infecções é realizado através da utilização sistemática de produtos antiparasitários. Muito embora todo programa parasitário efetivo incorpore a utilização de anti-helmínticos, o uso destes deve ser fundamentado no conhecimento epidemiológico e nas diferentes alternativas de pastoreio em relação ao risco parasitário (FIEL et al., 2001). Outra preocupação relevante é o potencial desenvolvimento da resistência parasitária (MOLENTO e PRICHARD, 1999).

Estudos demonstram as vantagens de administrar os tratamentos em menor freqüência. BIANCHIN (1991) determinou que a utilização de quatro tratamentos ao longo do ano apresenta eficácia semelhante quanto à administração de dois ou três tratamentos em relação ao ganho de peso de novilhos nelore. Estes dados revelam que pode ocorrer grande variabilidade entre o regime de tratamento e os ciclos estacionais. Já SANSON et al. (2003) relataram que a administração de três tratamentos com ivermectina possibilitou um ganho de peso de $61 \%$, comparado com o grupo controle, não-tratado, em novilhas de 14 meses, mestiças Angus e Brangus.

Notadamente, o valor nutritivo da pastagem também pode diminuir os efeitos deletérios da ação dos parasitas. O'KELLY et al. (1988) determinaram que pastagens de alta qualidade podem fornecer melhores condições físicas aos animais e não afetar o ganho de peso após a exposição aos parasitas comparado com animais em pastagem de baixa qualidade.

Embora existam relatos que comprovem a eficiência da utilização de compostos químicos, tais experimentos não esclarecem a relevância da nutrição na resposta a infecções naturais e ao desempenho zootécnico. O objetivo deste experimento foi associar o efeito da suplementação protéica e pastagem de alta qualidade com diferenças no grau de infecção parasitária em novilhas naturalmente infectadas.

\section{Material e Método}

O experimento foi realizado no município de Santa Maria - RS, latitude 2943' Sul e longitude $53^{\circ} 42^{\prime}$ Oeste. A região apresenta solo argissolo vermelho distrófico arênico, com clima subtropical úmido conforme classificação de Köppen. A área experimental foi dividida em quatro lotes, com área total de 11,7 ha. $O$ período de pastejo contínuo foi de 04 de julho a 01 de novembro de 2003, totalizando 120 dias.

Foram utilizadas 36 novilhas, 5/8 Charolês/ Nelore e 5/8 Nelore/Charolês, naturalmente infectadas, com idade e peso médio inicial de oito meses e $141,8 \mathrm{~kg}$, respectivamente. As amostragens (pesagem, escore corporal, colheita de amostras fecais e da pastagem) foram realizadas em intervalos de aproximadamente 21 dias. A pesagem dos animais foi realizada após jejum de 12 horas. Os animais foram divididos em quatro grupos, com nove animais: Grupo I: pastagem com alta carga de aveia (Avena strigosa) e azevém (Lolium multiflorum), Grupo II: pastagem e níveis crescentes de suplementação diária (Triticum aestivum, farelo de trigo), de 0,3;0,6;0,9;1,2 e $1,5 \%$ do peso vivo (PV) de suplemento durante cada ciclo, Grupo III: pastagem e 0,9\% do PV de suplemento e Grupo IV: pastagem e níveis decrescentes de suplementação (inverso grupo II).

O grau de infecção parasitária foi determinado através da contagem de ovos por grama de fezes (OPG) pela técnica de GORDON e WITHLOCK (1939) modificada. Foi realizada a cultura de fezes através da técnica 
Bezerras de corte infectadas naturalmente com parasitas gastrintestinais - epidemiologia e tratamento...

de Baermann para identificação dos gêneros presentes (UENO e GONÇALVES, 1998). Todo o animal, independente do grupo, que apresentou OPG acima de 600 foi tratado com levamisole (Ripercol ${ }^{\circledR}$, Fort Dodge) na dosagem recomendada pelo fabricante. Os animais foram tratados 40 dias antes de iniciar o experimento com o mesmo produto. Amostras da pastagem foram colhidas para determinação de formas infectantes (MOLENTO, 2001).

Foram realizadas correlações através da curva individual de ganho médio diário (GMD), ganho médio acumulado (GMA), nível de suplementação e grau de infecção parasitária para cada animal durante os períodos utilizando SAS/GLM (1998).

\section{Resultados e Discussão}

A coprocultura revelou prevalência dos gêneros Cooperia sp. e Trichostrongylus sp. (FIGURA 1). A dinâmica das infecções sugere uma competição direta, sendo necessário maior período de amostragens. A ocorrência de oocistos de Eimeria spp. foi crescente somente nas últimas três amostragens, possivelmente devido ao aumento da carga animal e do volume de chuvas na região. Foram detectadas
$12 \%$ de larvas de Ostertagia sp. na terceira amostragem. A determinação individual do OPG revelou que a distribuição é do tipo agregada e se ajusta no modelo binomial negativo (GRÁFICO 1). Em média 81,85\% (+/- 9,4\%) dos animais não foi tratado e $17,53 \%(+/-9,4 \%)$ recebeu tratamento, durante os períodos. HÖGLUND et al. (2001) observaram dados inferiores, onde $2,2 \%$ dos animais apresentaram OPG acima de 500 em 15 propriedades de bovinos orgânicos na Suécia. Observou-se a inexistência de variação entre as diferentes raças avaliadas.

Foram administradas 24 doses de antihelmíntico durante 120 dias, sendo que 11 animais receberam um tratamento, cinco animais foram tratados duas vezes e somente um animal foi tratado três vezes. Houve grande variação individual na resposta ao desafio parasitário entre períodos. Somente um animal não necessitou receber medicação antiparasitária. Nenhum animal manifestou sinais clínicos clássicos de parasitose. A eficácia média do composto químico utilizado foi de $94,7 \%$ (+/- 6,8\%) evidenciando a pouca pressão de seleção parasitária e a variabilidade do exame de OPG em testes de eficácia em bovinos.

GRÁFICO 1 - DISTRIBUIÇÃO DOS NÍVEIS DE OPG DURANTE OS PERÍODOS (P1-P6) DEAMOSTRAGENS.

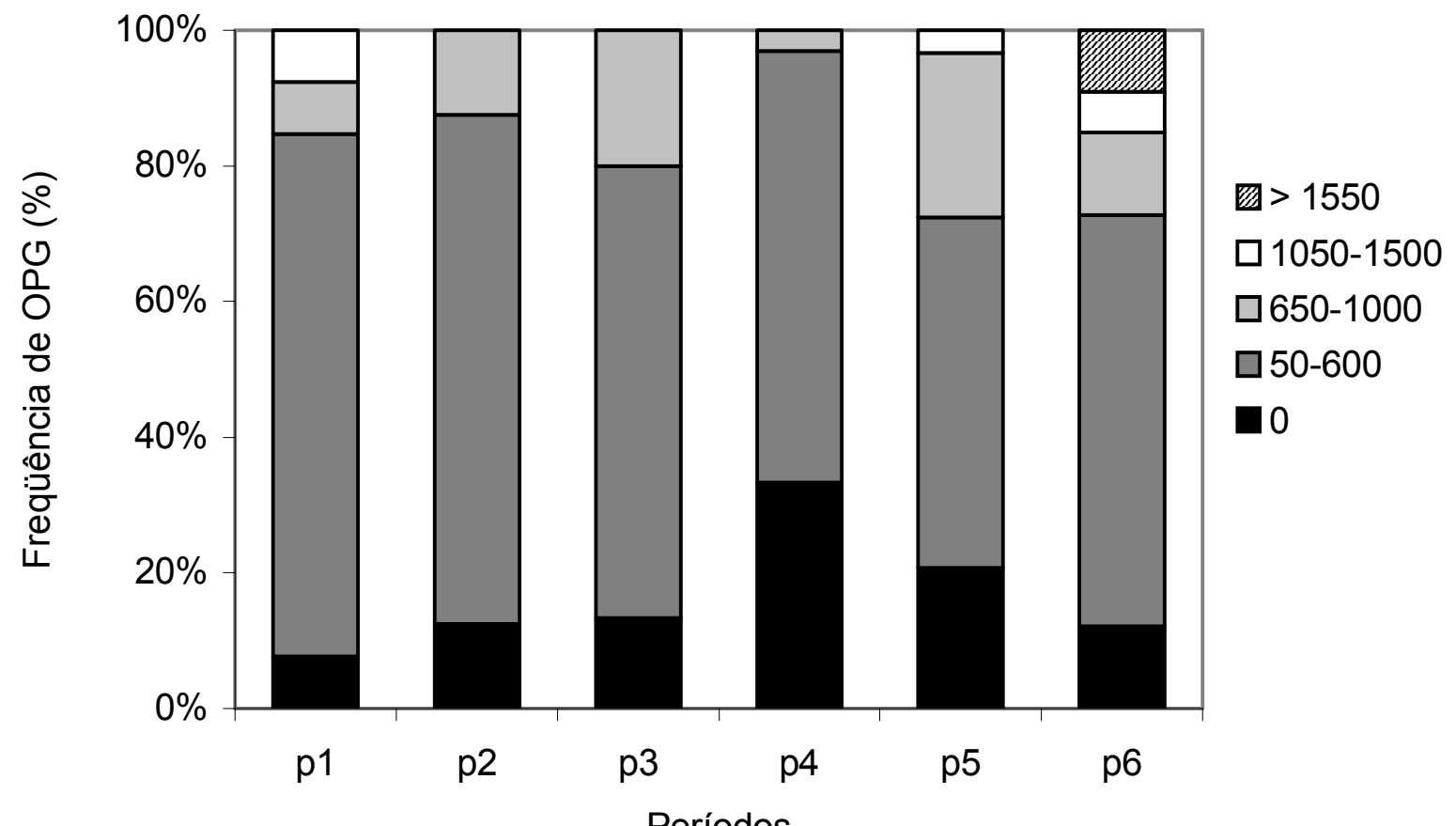

Archives of Veterinary Science v.10, n.1, p.45-50, 2005 
Animais que apresentaram níveis de infecção parasitária nula ou contagem de OPG leve, moderado ou grave (UENO e GONÇALVES, 1998) não diferiram estatisticamente em relação ao $\operatorname{GMD}(0,924 \mathrm{~kg} / \mathrm{dia})$, inclusive para aqueles animais que repetiram o tratamento antiparasitário. Dados semelhantes foram encontrados por NICOLAU et al. (2002), porém os animais daquele experimento foram tratados no início, na metade e no final do período de amostragens.

Durante as primeiras amostragens a determinação de larvas na pastagem foi nula, demonstrando baixo desafio parasitário. Somente nas três últimas amostragens ocorreu a presença de 348, 426 e 2987 larvas de estrôngilos/kg/MS respectivamente, com 15,5,
21,8 e $32,1 \%$ de matéria seca nos respectivos períodos. Foi observada ausência de correlação entre o aumento de larvas na pastagem e o ganho de peso.

Vários programas têm sido desenvolvidos para diminuir a pressão de seleção para resistência anti-helmíntica, sendo que a principal recomendação inclui a redução na freqüência de tratamentos. O princípio do controle seletivo é identificar e tratar exclusivamente os animais mais infectados dentro de um rebanho. Como foi demonstrado, pode ocorrer ainda o fenômeno de repetibilidade individual, sugerindo que os mesmos animais possam permanecer susceptíveis na repetição da amostragem durante uma determinada estação de pastejo.

FIGURA 1 - OCORRÊNCIA DOS GÊNEROS DE Cooperia sp. (LINHA TRACEJADA) E Trichostrongylus sp. (LINHA SÓLIDA) DURANTE OS PERÍODOS DE AMOSTRAGEM.

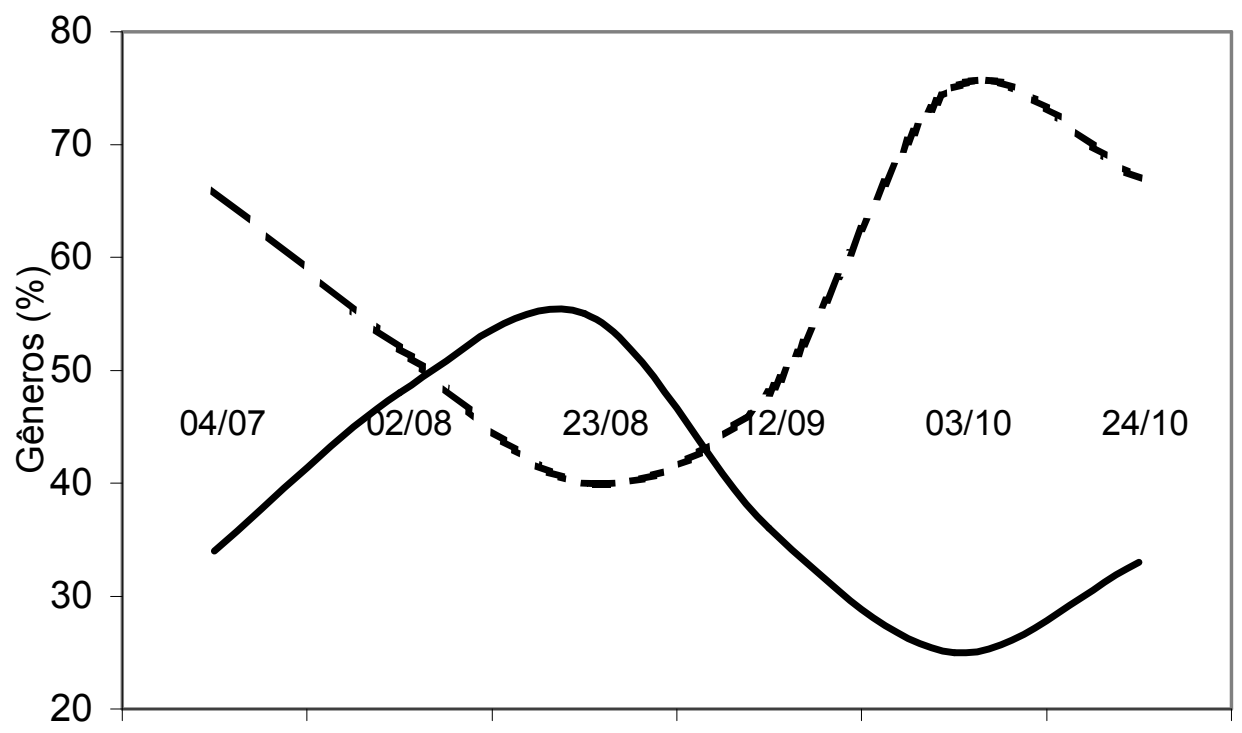

Amostragens

WALLER (1999) constatou que uma suplementação estratégica, particularmente para classes de animais susceptíveis como animais jovens e peri-parturientes, pode ser benéfica em longo prazo, reduzindo os níveis de infecção parasitária. Neste experimento, a utilização de pastagem de inverno de alta qualidade igualou a resposta dos hospedeiros frente às infecções, reduzido conseqüentemente a translação entre os períodos e o desafio parasitário.

Outra preocupação é a manutenção da população em refugia que é responsável pela característica susceptível de larvas e adultos. Neste particular o tratamento seletivo permite que um grande número de parasitas não seja exposto ao produto utilizado, favorecendo a população susceptível. Segundo HOSTE et al (2002), o ponto chave do tratamento seletivo, reside na identificação do animal mais 
Bezerras de corte infectadas naturalmente com parasitas gastrintestinais - epidemiologia e tratamento...

susceptível dentro do grupo, o qual é responsável pela maior parte da contaminação da pastagem. Teoricamente, o controle parasitário efetivo pode ser efetuado se apenas esses indivíduos que carregam alta carga parasitária (worm taxis) forem tratados. No presente experimento, os dados clínicos não foram suficientes para selecionar animais para tratamento. EPPERSON et al. (2001) sugerem o tratamento de um pequeno lote de animais de forma aleatória tem a capacidade de manter um número aceitável de parasitas nos hospedeiros não tratados e na pastagem, não ocorrendo perdas zootécnicas significativas.

Quando comparado com os estudos descritos acima, os dados colhidos neste experimento demonstram a possibilidade de uma economia entre 300 e $450 \%$ na utilização de compostos antiparasitários. Esta comparação foi determinada a partir da média de tratamentos antiparasitários anualmente utilizados em bovinos na região de Santa Maria, RS (Molento, informação pessoal).

\section{Conclusões}

Foi determinado que o tratamento seletivo baseado em exames laboratoriais pode ser aplicado quando os animais dispõem de pastagem de alta qualidade, independente de suplementação alimentar, promovendo elevada redução no uso de medicação antiparasitária. No entanto, ainda é desconhecida a proporção ideal para tratamento no caso de avaliações em animais com infecções sub-clínicas. Neste caso, deve-se acompanhar o ganho de peso de animais tratados e não-tratados para melhor utilizar a estratégia de tratamento seletivo. Esta forma de controle pode ser utilizada para preservar a eficácia dos compostos químicos promovendo a diminuição da pressão de seleção em populações parasitárias, incrementando a relação custobenefício e mantendo a população em refugia.

\section{REFERÊNCIAS}

BIANCHIN, I. Epidemiologia e controle de helmintos gastrintestinais em bezerros a partir da desmama, em pastagem melhorada, em clima tropical do Brasil. Rio de Janeiro, 1991. 162p. Tese (Doutorado) - Universidade Federal do Rio de Janeiro.
BISHOP, S.C.; STEAR, M.J. Modeling of host genetics and resistance to infections diseases: understanding and controlling nematode infections. Veterinary Parasitology, New Jersey, v.115, p.147166, 2003.

EPPERSON, W.B.; KENZY, B.D.; MERTZ, K.; HILDRETH, M.B. A single pasture limited treatment approach to estimate production loss from gastrointestinal nematodes in grazing stocker cattle. Veterinary Parasitology, New Jersey, v.97, p. 269276, 2001.

FIEL, C.; ANZIANI, O.; SUÁREZ, V.; VÁZQUES, R.; EDDI, C.; ROMERO, J.; CARACOSTANTOGOLO, J.; SAUMELL, C.; MEJÍA, M.; COSTA, J.; STEFFAN, P. Resistencia anti-helmíntica en bovinos: causas, diagnóstico y profilaxis. Veterinária Argentina, Buenos Aires, v.18, p.21-33, 2001.

GORDON, H.M.; WITHLOCK, H.V. A new technique for counting nematode eggs in sheep faeces. Journal of the Council for Scientific and Industrial Research, Melbourne, v.12, p.50-52, 1939.

HÖGLUND, J.; SVENSSON, C.; HESSLE, A. A field survey on the status of internal parasites in calves on organic dairy farms in southwestern Sweden. Veterinary Parasitology, New Jersey, v.99, p.113128, 2001.

HOSTE, H.; LE FRILEUX, Y.; POMMARET, A. Comparison of selective and systematic treatments to control nematode infections of the digestive tract in dairy goats. Veterinary Parasitology, New Jersey v.106, p.345-355, 2002.

MOLENTO, M.B.; PRICHARD, R.K. Nematode control and the possible development of anthelmintic resistance. Revista Brasileira de Parasitologia Veterinária, São Paulo, v.8, p.7586, 1999.

MOLENTO, M.B. Técnica de contagem de larvas no pasto como ferramenta para diagnóstico parasitológico. In: Simpósio da Rede de Helmintologia para América Latina e Caribe, 2, 2001, Buenos Aires. Anais.... Buenos Aires, 2001. CDROM.

NICOLAU, C.V.J.; AMARANTE, A.F.T.; ROCHA, G.P.; GODOY, W.A.C. Relação entre desempenho e infecções por nematódeos gastrintestinais em bovinos nelore em crescimento. Arquivo Brasileiro de Medicina Veterinária e Zootecnia, Belo Horizonte, v.54, p.1-10, 2002.

O'KELLY, J.C.; POST, T.B.; BRYAN, R.P. The influence of parasitic infestation on metabolism, puberty and first mating performance of heifers grazing in a tropical area. Animal Reproduction Science, New York, v.16, p.177-189, 1988. 
SANSON, D.W.; DEROSA, A.A.; OREMUS, G.R.; FOIL, L.D. Effect of horn fly and internal parasite control on growth of beef heifers. Veterinary Parasitology, New Jersey, v.117, p.191-300, 2003.

SAS INSTITUTE. Statistical Analysis System Software Release 6. 12TS020 for Windows. University of North Carolina, 1998.

UENO, H.; GONÇALVES, P.C.Manual para diagnóstico das helmintoses de ruminantes. 4.ed. Tokyo: Japan International Cooperation Agency, 1998, 143 p.

Recebido para publicação: 04/11/2004

Aprovado:
VERCRUYSSE, J.; DORNY, P. Integrated control of nematode infections in cattle: a reality? a need? a future? International Journal for Parasitology, Sydney, v.29, p.165175, 1999.

WALLER, P. J. International approaches to the concept of integrated control of nematode parasites of livestock. International Journal of Parasitology, Sydney, v.29, p.155-164, 1999. 